\title{
Health beliefs among African American women regarding genetic testing and counseling for sickle cell disease
}

Shanna L. Gustafson, $M S^{1,3}$, Elizabeth A. Gettig, MS, CGC $C^{1}$, Margaret Watt-Morse, $M D^{2}$, and Lakshmanan Krishnamurti, $M D^{3}$

\begin{abstract}
Purpose: The Health Belief Model can help in understanding low acceptance of disease prevention and screening. We studied health beliefs of African American women to determine causes of low acceptance of genetic testing and counseling despite high prevalence of sickle cell disease and heterozygotes in this population. Methods: An anonymous questionnaire using a 12-question measure with a 5-point Likert scale response was administered to 101 African American women attending an obstetrics and gynecology clinic to determine knowledge of sickle cell disease, perception of risk, severity, likelihood of benefit and barriers to counseling. Results: The cumulative mean perceived scores on the 5 -point Likert scale were $4.22 \pm 0.88$ for severity of sickle cell disease, $4.10 \pm 1.03$ for benefit of genetic testing, $2.28 \pm 1.00$ for barriers to testing, and $2.62 \pm 1.06$ for risk of having a child with sickle cell disease. High average level knowledge was associated with high perception of severity and benefit to screening $(P<0.05)$. Conclusion: African American women have a relatively high belief of the severity of sickle cell disease and benefits of genetic counseling but frequently do not appear to believe that they are at risk of having a child with the disease. This should be taken into account in the design of educational and counseling strategies. Genet Med
\end{abstract} 2007:9(5):303-310.

Key Words: Health Belief Model, population screening, sickle cell trait, hemoglobinopathy, sickle cell disease

Sickle cell disease (SCD) is a common single gene disorder most prevalent among persons of African descent, although many other ethnic groups may also be affected. In the United States, an estimated one in every 375 live births among individuals of African descent is affected by SCD, and approximately 1 in every 12 African Americans is a heterozygous carrier of the sickle $\beta$-globin mutation. ${ }^{1-3}$

Newborn screening for hemoglobinopathies has been a successful form of population screening for SCD, with the majority of states establishing programs of screening for hemoglobinopathies by the mid-1980s. ${ }^{4}$ The primary purpose of the newborn screening program has been to identify newborns with SCD and initiate penicillin prophylaxis because this has shown to substantially reduce the incidence of pneumococcal sepsis in infancy. ${ }^{4-6}$ In the course of screening for SCD, heterozygous carriers of the sickle cell trait (SCT) are also identi-

\footnotetext{
From the ${ }^{1}$ Genetic Counseling Program, University of Pittsburgh, Pittsburgh, Pennsylvania; ${ }^{2}$ Division of Hematology/Oncology/Bone Marrow Transplantation, Magee-Women's Hospital; ${ }^{3}$ Children's Hospital of Pittsburgh, Pittsburgh, PA.

Lakshmanan Krishnamurti, MD, Division of Hematology/Oncology/Bone Marrow Transplantation, Children's Hospital of Pittsburgh, 3705 Fifth Avenue, Pittsburgh, PA 15213; E-mail: krislx@chp.edu

The authors declare no conflict of interest.
}

Submitted for publication October 26, 2006.

Accepted for publication February 26, 2007.

DOI: 10.1097/GIM.0b013e3180534282 fied. Although this offers the opportunity for counseling a family who may be at risk of having a child with SCD in a future pregnancy, no universally accepted method of notification and counseling has proven to be effective. ${ }^{3,7-10}$

Knowledge of SCD, cultural views, health beliefs, and social and economic barriers may be contributors to the lack of interest and support for SCT testing and genetic counseling among African Americans. The Health Belief Model can help to understand the failed acceptance of disease prevention and screening services among various populations. ${ }^{11}$ Health screening behavior is determined to be driven by a combination of (1) the individual's perceived susceptibility to the condition, (2) the individual's perceived seriousness of the condition, (3) the individual's perceived benefit of the specific behavior, and (4) the individual's perceived barriers to the behavior. ${ }^{12}$

Use of the Health Belief Model has been successful in assessing and motivating health behavior change among African Americans in regards to cancer screening, genetic information, and use of health care resources for sickle cell patients, prenatal screening for hemoglobinopathies, diabetic health care compliance, and sexual practices over a range of age groups. ${ }^{13-41}$ Health beliefs may differ between African Americans and other ethnic groups. ${ }^{21,42}$ African American women who perceive fewer barriers to screening perceive more benefits to pursuing screening, have an increased perception of susceptibility, and have confidence in the accuracy of screening are more likely to undergo screening for cancer. ${ }^{22,25,26}$ Increased understanding 
and knowledge of screening methods and the disease state also affect participation in screening. $22,25,26$

An assessment of the influences motivating African Americans to pursue testing and counseling for SCD may be beneficial in designing approaches to education and counseling. We therefore undertook an investigation of the current state of health beliefs among African American women toward SCD and SCT screening and counseling.

\section{METHODS AND MATERIALS}

African American women, older than the age of 18 who were visiting the laboratory of the Magee-Women's Hospital Outpatient Obstetrics and Gynecology Clinic were invited to participate in an anonymous self-administered survey and short educational session regarding SCD and SCT. The study, anonymous surveys, and educational materials used were reviewed and approved by the University of Pittsburgh Institutional Review Board. Participants included women who were pregnant and women who were receiving routine gynecological care. Anonymous surveys to evaluate the health beliefs and knowledge of SCD were given to voluntary participants before participation in a brief 5-minute educational discussion session regarding SCD and SCT screening. A representation of the survey questions used can be found in Table 1 . The assessment was performed before educating the population to avoid influencing the answers and to obtain a representative sample of the current state of knowledge and the health beliefs of the African American female population. Knowledge of SCD was assessed using eight multiple-choice questions modeled after a survey administered to school-age children to assess knowledge of $\mathrm{SCD}^{43}$ and experience with SCT carrier education. The health beliefs survey is a 12-question measure modeled after those used among African American women to assess motivations for participation in cancer screening programs. ${ }^{21,42} \mathrm{~A}$ 5-point Likert scale response system was used to assess the health beliefs of perceived susceptibility, perceived seriousness, perceived benefit of action, and perceived barriers to action. A score of 1 indicated strongly disagree or a low level of perception, and 5 indicated strongly agree or a high level of perception, as recommended by Champion..$^{12}$ Five demographic questions were also obtained. After participation of 45 individuals, it was deemed useful to also inquire whether the participants had been previously screened and whether they were found to be carriers as this information may be related to the level of perceived susceptibility and the level of knowledge regarding SCD and SCT. Correct answers to the SCD knowledge questions were given a score of 1 , with a total maximum possible score of 8. A 5-point Likert scale was used for assessment of perceived severity, susceptibility, benefits, and barriers, with 5 indicating a high perception and 1 indicating a low perception. Stata 7.0 statistical software was used for descriptive statistics, linear regression and correlation studies. A $P$ value of $\leq 0.05$ was considered statistically significant.

\section{RESULTS}

\section{Demographics}

One hundred one women, age 18 to 45 years old (median, 24 years) at least partially completed the health beliefs survey. Demographics of the participants are described in Table 2. The majority of the population surveyed for knowledge of SCD and perceived health beliefs had attended some college (39\%) and were unmarried (58\%), with an average of one child (27.2\%). Forty-one percent of participants currently live with their partner. Fifty-five participants were surveyed on whether they had previously been tested for SCT; of these participants, 16 (29.09\%) indicated they had been previously tested and two of those $(12.5 \%)$ indicated that they had SCT.

\section{Perceived health beliefs}

The cumulative mean perceived severity before education was $4.22 \pm 0.88$ on the 5 -point Likert scale. Respondents' levels of perception that SCD is a serious disease, that having a child with the disease would be scary, and that it would change their life were 4.40,4.42, and 3.81, respectively, on a 5-point Likert scale. The cumulative perceived benefit to testing was $4.10 \pm$ 1.03. Respondent's levels of perception that it would be useful to know their own trait status, to know the trait status of their partners, and perception that it may influence how they would plan their pregnancy were $4.32,4.43$, and 3.58 , respectively, on the 5-point scale. The cumulative perceived barriers to testing were $2.28 \pm 1.00$. Respondent's perceptions that the testing was painful and difficult and that it would be difficult to convince their partner to be tested were 2.18 and 2.10 , respectively. The perception of a financial barrier in the form of desiring to pay for testing in the event it was not covered by insurance was 2.59 on a 5 -point Likert scale. The cumulative perceived susceptibility was $2.62 \pm 1.06$ on the 5 -point Likert scale. Respondents' perceptions that their partner may have SCT, that their own children were at risk of having SCD, and that the disease could happen in their family were $2.45,2.05$, and 3.329 , respectively. It is of note that the perceived risk to extended family is relatively higher than that of the immediate risk to their own children. All data can be seen in Figure 1. Of the 55 participants who were questioned on whether they had been screened previously, no significant relationship was found between having been screened and their perceived severity of SCD, their perceived susceptibility, their perceived benefits to testing, and their perceived barriers to testing.

\section{Knowledge}

The average knowledge score on an eight-question scale was $4.46 \pm 1.83$. The Spearman rank correlation function was used to determine correlation between overall knowledge of SCD and the health beliefs. Spearman's $\rho$ value of 1 indicates a perfect positive correlation, a $\rho$ of -1 indicates a perfect negative correlation, and a $\rho$ of 0 indicates that the values are completely independent of each other. A positive correlation was found between the average level of knowledge and the perceived severity of SCD and between the level of knowledge and the 
Table 1

Questionnaire for assessment of knowledge and health beliefs of sickle cell disease

Knowledge questions: the following are some questions about sickle cell disease

1. Sickle cell disease is caused by

2. How many genes must someone inherit to have sickle cell disease?

3. Sickle cell disease can cause

4. Sickle cell disease occurs most often in

5. Sickle cell pain can feel worse than

6. Sickle dell disease makes red blood cells

7. Sickle cell disease is easily cured by

8. How can you tell if someone carries the gene for sickle cell disease
Please read each question very carefully and then circle one answer that is best. Remember only one answer for each question

$\%$ of participants who answered correctly $(N=101)$

a. Dirty needles

79.2

b. A virus

c. Inheriting genes from parents

d. Bad blood

e. None of the above

a. Zero, it is not caused by genes

49.5

b. One from their mom

c. Two, one from the mother and one from the father

$\mathrm{d}$. Three, one from the mother and two from the father

e. None of the above

a. Severe debilitating pain

b. Strokes

c. Infections

d. Organ damage

e. All of the above

a. Boys

b. Girls

c. White people

d. Black people

e. All of the above

a. A broken bone

b. A headache

c. A gunshot wound

d. All of the above

e. None of the above

a. Round and soft

b. Hard and sickle shaped

c. Sticky and blue

d. Stiff and round

e. Soft and sickle shaped

a. Antibiotics

b. Liver transplant

c. Rest

d. Blood transfusions

e. None of the above

a. They look sick

b. They will eventually have sickle cell disease

c. With a simple blood test

d. There is no way of knowing

e. None of the above 
Table 1

Continued

Knowledge questions: the following are some questions about sickle cell disease

Health beliefs questions

\section{Severity}

1. Sickle cell disease is a serious disease

2. Having a child with sickle cell disease would be very scary

3. My life would change if I had a child with sickle cell disease Susceptibility

4. My children are at risk of sickle cell disease

5. Sickle cell disease could happen in my family

6. My partner may be a carrier of sickle cell trait

Benefit

7. It is useful to know whether I have the sickle cell trait

8. It is useful to know whether my partner has the sickle cell trait

9. Knowing the risk of having a child with sickle cell disease would change how I plan a pregnancy

Barriers

10. Testing for the sickle cell trait is painful and difficult

11. My partner would be hard to convince to be tested

12. I would not want to pay for sickle cell trait testing if it is not paid for by insurance

Demographic questions

1. I am years old

2. I am children

3. I have

4. I live with my partner
Please read each question very carefully and then circle one answer that is best. Remember only one answer for each question

$\%$ of participants who answered correctly $(N=101)$

Please rate your level of agreement with each of the following statements

Strongly disagree 12345 Strongly agree

Strongly disagree 12345 Strongly agree

Strongly disagree 12345 Strongly agree

Strongly disagree 12345 Strongly agree

The following questions tell us more about you. Please circle or fill in the answer that best describes you.
18-19
$20-24$
25-29
$30-34$
35-39
35-39
40-44
45

Single

Married

Divorced

In a relationship

0
1
2
3
4
$5+$

Do

Do not

No partner 
Table 1

Continued

\begin{tabular}{|c|c|c|}
\hline $\begin{array}{l}\text { Knowledge questions: the following are some questions about } \\
\text { sickle cell disease }\end{array}$ & $\begin{array}{l}\text { Please read each question very carefully and then circle } \\
\text { one answer that is best. Remember only one answer } \\
\text { for each question }\end{array}$ & $\begin{array}{l}\text { \% of participants who } \\
\text { answered correctly }(N=101)\end{array}$ \\
\hline \multirow[t]{4}{*}{ 5. The highest level of school I have finished is } & Some high school & - \\
\hline & Some college & \\
\hline & College graduate & \\
\hline & Graduate/professional school & \\
\hline \multirow[t]{3}{*}{ 6. Have you ever been tested for sickle cell trait? ${ }^{a}$} & Yes & - \\
\hline & No & \\
\hline & I don't know & \\
\hline \multirow{3}{*}{$\begin{array}{l}\text { 7. If you have been tested, were you found to have sickle cell } \\
\text { trait? }^{a}\end{array}$} & Yes & - \\
\hline & No & \\
\hline & I don't know & \\
\hline
\end{tabular}

${ }^{a}$ Additional questions asked of 55 participants, added to survey late.

Table 2

Demographics of women who completed the survey

\begin{tabular}{lcc}
\hline Demographic variable & $\%$ & No. \\
\hline Marital status $(n=100)$ & 58.0 & 58 \\
Single/divorced & 12.0 & 12 \\
Married & 30.0 & 30 \\
In a relationship & & \\
No. of children $(n=99)$ & 25.3 & 25 \\
0 & 27.3 & 27 \\
1 & 24.3 & 24 \\
2 & 19.2 & 19 \\
3 & 0.4 & 4 \\
$4+$ & & \\
Living situation $(n=100)$ & 41.0 & 41 \\
With partner & 59.0 & 59 \\
Do not live with partner/no partner & & 78 \\
Education $(n=100)$ & 18.0 & 30 \\
Some high school & 30.0 & 39 \\
High school graduate & 39.0 & 7.0 \\
Some college & 6.0 & \\
College graduate & & \\
Graduate/professional school & & \\
\hline
\end{tabular}

perceived benefit to testing with a $P$ value $<0.05$. A statistically significant correlation was not found between the average total knowledge of SCD score and the perceived susceptibility and perceived barriers to testing. Further analysis of each knowledge question in relation to the perceived health beliefs found a statistically significant positive correlation between understanding of recessive inheritance and perceived severity, susceptibility, and benefits with a $P$ value $<0.05$. Additional pos- itive correlation was found between perceived severity and understanding that SCD is genetic, symptoms are severe, etiology of SCD, and understanding identification of SCT carriers. A positive correlation between perceived benefits of testing and an understanding of SCD etiology and identification of SCT carriers was also observed (Table 3 ).

Linear regression was used to determine a relationship between the demographic data and the average health beliefs. Perceived severity was significantly predicted by knowledge of SCD only, with a $P$ value $<0.05$. Perceived susceptibility to SCD was found to correlate significantly with age. Perceived benefits to testing and perceived barriers to testing were not significantly predicted by any of the demographic variables available.

\section{DISCUSSION}

The Health Belief Model theorizes that pursuit of a health screening program will occur when an individual believes that the health concern is serious enough to warrant screening and that he or she is at risk of the disorder and believes that there is a benefit to pursuing the screening and that the barriers to pursuing screening are low. ${ }^{11,15}$ The Health Belief Model has been used in many studies concerning screening among the Ashkenazi Jewish population. This research provides a novel look into the beliefs of the African American population on screening for SCT.

The results of this study suggest that African American women of childbearing age believe that SCD is a severe disease, that there are benefits to screening for SCT, and that the barriers to screening are relatively low. However, they also appear to perceive a lower level of personal susceptibility to having a child with SCD. According to the Health Belief Model, in order to be motivated to pursue a health screening behavior an individual must believe that they are in fact at risk. ${ }^{11,12,15,44}$ The low perception of susceptibility to having a child with SCD is one 


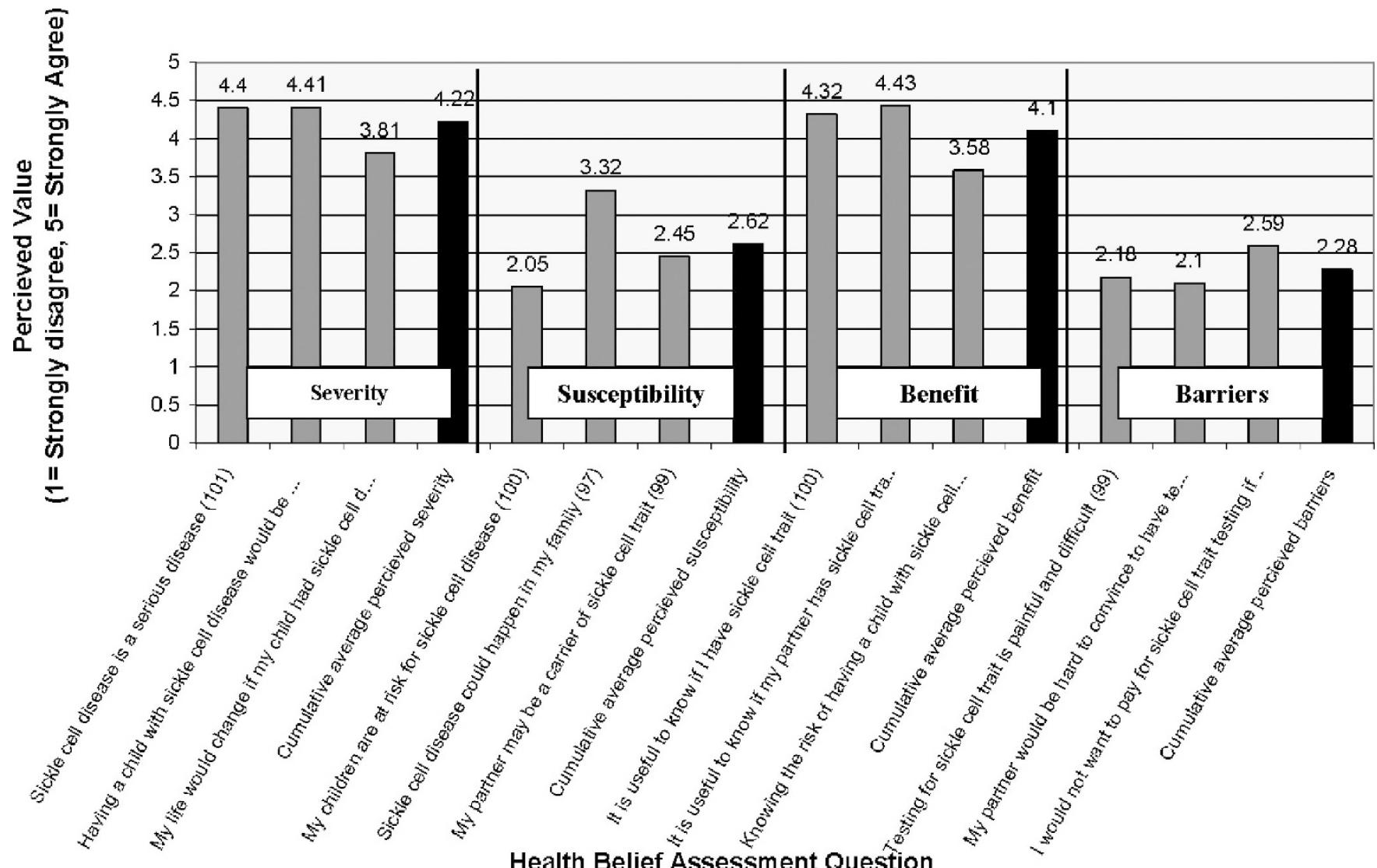

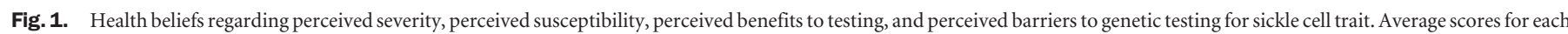

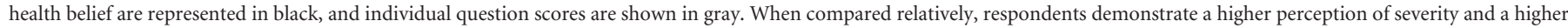
perception of benefit to testing than a perception of susceptibility and barriers to testing.

potential explanation for the low uptake of genetic testing and counseling for this disorder as has been observed by many investigators. ${ }^{3,9,10}$

Interestingly, in the educational discussions that took place after administration of the questionnaires, the comment "Sickle cell disease just doesn't run in my family," was repeatedly volunteered by participants to the researcher. This repeated comment leads us to speculate that the health beliefs may be related to established family or cultural scripts. Family scripts are sets of expectations, beliefs, and norms that assign meaning to patterns of interaction, connect generations, and provide guidance for action. ${ }^{45}$ These scripts include beliefs regarding health and illness and the preferred steps to treatment, sharing of information, and roles of family members. ${ }^{46} \mathrm{~A}$ family's beliefs are influenced by sociocultural history, spiritual practices, and experience and can play a significant role in genetic counseling situations. ${ }^{46}$ Sensitivity to and awareness of these family and cultural scripts may be important to connect with patients and successfully educate these families. ${ }^{46}$ It is possible that the absence of disease in their extended family may add to the belief that they are not at risk of having a child with SCD, and this should be researched further.

Education is often proposed as the most effective way of promoting screening behaviors. An increased level of average SCD knowledge was found to be significantly related to a high perceived severity to SCT and the perceived benefit to SCT screening. It is possible that those individuals with personal experience with SCD, such as afflicted friends or family, will know more about SCD and have experienced its severity and so may feel the screening is more beneficial for preventing future children affected with SCD. However, this study found no relationship between average knowledge of SCD and the perceived level of susceptibility to having a child with SCD. However, positive correlation was observed between an understanding of recessive inheritance and perceived susceptibility to having a child with SCD. It is thus possible that because only half of the respondents understood recessive inheritance, no overall association between knowledge and perceived susceptibility was observed. This suggests the need for and the potential impact of culturally appropriate methods for teaching complex genetic concepts such as autosomal recessive inheritance.

In screening for Tay-Sachs disease among the Ashkenazi Jewish population, anxiety and fear may also have served as motivation for screening; however, this can often result in decisions based on emotion and not based on information. ${ }^{47}$ One of the major recommendations of the Task Force on Genetic Testing of National Institutes of Health Department of Energy Working Group on Ethical, Legal, and Social Implications of 
Table 3

Correlation of knowledge of SCD and health beliefs

\begin{tabular}{|c|c|c|c|c|}
\hline & Severity & Susceptibility & Benefits & Barriers \\
\hline \multicolumn{5}{|c|}{ Total knowledge score } \\
\hline Spearman's $\rho$ & 0.4089 & 0.1656 & 0.3344 & 0.0121 \\
\hline$P$ & 0.0000 & 0.1068 & 0.0009 & 0.9056 \\
\hline \multicolumn{5}{|l|}{ 1. SCD is genetic } \\
\hline Spearman's $\rho$ & 0.2757 & 0.0434 & 0.1425 & 0.0180 \\
\hline$P$ & 0.0053 & 0.6746 & 0.1662 & 0.8606 \\
\hline \multicolumn{5}{|c|}{ 2. SCD recessive inheritance } \\
\hline Spearman's $\rho$ & 0.3072 & 0.2041 & 0.2593 & 0.0292 \\
\hline$P$ & 0.0018 & 0.0461 & 0.0107 & 0.7757 \\
\hline \multicolumn{5}{|l|}{ 3. SCD symptoms } \\
\hline Spearman's $\rho$ & 0.1466 & 0.0967 & 0.0744 & 0.0582 \\
\hline$P$ & 0.1435 & 0.3487 & 0.4711 & 0.5692 \\
\hline \multicolumn{5}{|c|}{ 4. At-risk population } \\
\hline Spearman's $\rho$ & -0.0367 & 0.0521 & -0.0104 & -0.0271 \\
\hline$P$ & 0.7153 & 0.6145 & 0.9199 & 0.7914 \\
\hline \multicolumn{5}{|c|}{ 5. Severity of symptoms } \\
\hline Spearman's $\rho$ & 0.3054 & -0.0639 & 0.0529 & 0.1436 \\
\hline$P$ & 0.0019 & 0.5365 & 0.6085 & 0.1583 \\
\hline \multicolumn{5}{|l|}{ 6. SCD etiology } \\
\hline Spearman's $\rho$ & 0.3609 & 0.0957 & 0.2492 & 0.1712 \\
\hline$P$ & 0.0002 & 0.3537 & 0.0144 & 0.0919 \\
\hline \multicolumn{5}{|l|}{ 7. SCD treatments } \\
\hline Spearman's $\rho$ & 0.1434 & 0.0100 & 0.1996 & -0.1218 \\
\hline$P$ & 0.1524 & 0.9227 & 0.0512 & 0.2323 \\
\hline \multicolumn{5}{|c|}{ 8. SCT identification } \\
\hline Spearman's $\rho$ & 0.2717 & 0.1624 & 0.2467 & -0.1577 \\
\hline$P$ & 0.0060 & 0.1140 & 0.0154 & 0.1210 \\
\hline
\end{tabular}

SCD, sickle cell disease, SCT, sickle cell trait.

Human Genome Research is that genetic screening programs must be sensitive to the individual cultural needs of the groups being screened and that the patients, physicians, and genetic counselors fully understand the testing procedures and ensure validity to guarantee that patients make fully informed, autonomous decisions about the testing. ${ }^{48-50}$ The findings of this study give some indications of weakness in current community education on genetic testing and counseling for SCD among African American women and point to the need for further investigation that can lead to the development of culturally sensitive and effective methods for genetic education among the African American population. Similar studies are also warranted for other patient populations, such as the at-risk Hispanic population, as health beliefs can vary between cultures.

This study is limited by the fact that the participants were only women who were actively pursuing health care. It is pos- sible that these women represent a population that may already have a higher understanding and acceptance of health care and testing. As the largest prenatal health care facility in the Pittsburgh area, Magee-Women's Hospital provides care for people of all socioeconomic and education statuses. Information from the 2006 United States Census bureau indicates that $81.2 \%$ of African American women are at least high school graduates and $18.8 \%$ of African American women attain a college undergraduate degree or more..$^{51}$ In the Pittsburgh metropolitan area and Allegheny County, $13 \%$ of African Americans are at least college graduates and $18 \%$ are high school dropouts. Thus, subjects surveyed on this study appear to be representative of the African American female population. Another limitation of this study is that we did not assess whether all the participants had had previous education on SCD and SCT or whether the participants had ever been tested for SCT. It is possible that those who have had testing and genetic counseling before participating would have an increased level of acceptance of testing and counseling and an increased previous education on the disorder. However, of the 55 participants who were surveyed on previous screening experience, no correlation was found between the health beliefs or knowledge of SCD. Acceptance of genetic counseling may be affected by a willingness to consider termination of pregnancy if prenatal testing reveals a fetus affected by disease; however, the goals of this study were not to investigate the attitudes of participants toward termination of pregnancy. Experience with Tay-Sachs disease in the United States and with $\beta$-thalassemia in Cyprus suggests that community awareness of and active involvement in a screening program can have a major impact on reproductive decisions made by couples at risk of having a child with the disease. However, the clinical course in SCD is less predictable and there is limited experience in genetic education and counseling in the African American community. It is therefore unknown whether education and counseling will ultimately affect reproductive choices made by couples. Further, because we collected only limited demographic data in the brief questionnaire, we did not investigate the impact of socioeconomic status or availability of transportation on health beliefs.

In conclusion, African American women of childbearing age appear to have a good understanding of the severity of SCD, the benefits of genetic testing and counseling, and the relatively low barriers to obtaining this testing, but frequently do not believe that their personal risk of having a child with SCD is high. These health beliefs must be taken into account when designing programs for African American women on genetic testing and counseling for SCD. Further study is indicated to determine why African American women do not believe that they are at risk of having children with SCD and what impact socioeconomic status has on these beliefs.

\section{ACKNOWLEDGMENT}

This study was supported by HRSA grant 6H46MC $00255-$ 01-01. 


\section{References}

1. Lonergan GJ, Cline DB, Abbondanzo SL. Sickle cell anemia. Radiographics 2001;21: 971-994.

2. Doris L, Wethers MD. Sickle Cell Disease in Childhood: Part I. Laboratory Diagnosis, Pathophysiology and Health Maintenance. American Family Physician 2000;62: 1013-1020.

3. Kladny B, Gettig EA, Krishnamurti L. Systematic follow-up and case management of the abnormal newborn screen can improve acceptance of genetic counseling for sickle cell or other hemoglobinopathy trait. Genet Med 2005;7:139-142.

4. National Newborn Screening and Genetics Resource Center: current newborn screening (NBS) conditions by state. U.S. National Newborn Screening Status Report, Vol. 2006. Austin, TX: NNSGRC; 2006; available at: http://genes-r-us.uthscsa. edu/nbsdisorders.pdf.

5. Gaston MH, Verter JI, Woods G Pegelow C, et al. Prophylaxis with oral penicillin in children with sickle cell anemia. A randomized trial. N Engl J Med 1986;314:15931599.

6. Powars DR, Hiti A, Ramicone E, Johnson C, et al. Outcome in hemoglobin SC disease: a four-decade observational study of clinical, hematologic, and genetic factors. Am J Hematol 2002;70:206-215.

7. Grossman LK, Holtzman NA, Charney E, Schwartz AD. Neonatal screening and genetic counseling for sickle cell trait. Am J Dis Child 1985;139:241-244.

8. Anonymous. National Newborn Screening Report - 2000 Austin, TX National Newborn Screening and Genetics Resource Center 2003.

9. Miller ST, Stilerman TV, Rao SP, Abhyankar S, et al. Newborn screening for sickle cell disease. When is an infant 'lost to follow-up'? Am J Dis Child 1990;144:13431345 .

10. Hurst D. Newborn screening for sickle cell disease and other hemoglobinopathies. Northern California's experience. Pediatrics 1989;83:868-871.

11. Janz NK, Becker MH. The Health Belief Model: a decade later. Health Educ Q 1984; 11:1-47.

12. Champion VL. Instrument development for health belief model constructs. $A d v$ Nurs Sci 1984;6:73-85.

13. Ashing-Giwa K. Health behavior change models and their socio-cultural relevance for breast cancer screening in African American women. Women Health 1999;28: 53-71.

14. Brown CM, Segal R. The effects of health and treatment perceptions on the use of prescribed medication and home remedies among African American and white American hypertensives. Soc Sci Med 1996;43:903-917.

15. Brown KM. Health Belief Model. Vol. 2005; 2005, hsc.usf.edu/kmbrown/Health Belief_Model_Overview.htm:Health Belief Model Overview.

16. Byrne M, Walsh J, Murphy AW. Secondary prevention of coronary heart disease: patient beliefs and health-related behavior. J Psychosom Res 2005;58:403-415.

17. Douglass M, Bartolucci A, Waterbor J, Sirles A. Breast cancer early detection: differences between African American and white women's health beliefs and detection practices. Oncol Nurs Forum 1995;22:835-837.

18. Doukas D Localio A Li Y. Attitudes and beliefs concerning prostate cancer genetic screening. Clin Genet 2004;66.

19. Elliott V, Morgan S, Day S, Mollerup LS, et al. Parental health beliefs and compliance with prophylactic penicillin administration in children with sickle cell disease. J Pediatr Hematol Oncol 2001;23:112-116.

20. Farquharson L. Noble L, Barker C, Behrens R. Health beliefs and communication in the travel clinic consultation as predictors of adherence to malaria chemoprophylaxis. Br J Health Psychol 2004;9.

21. Foxall MJ, Barron CR, Houfek J. Ethnic differences in breast self-examination practice and health beliefs. J Adv Nurs 1998;27:419-428.

22. Frank D, Swedmark J, Grubbs L. Colon cancer screening in African American women. ABNF J 2004;15.

23. Gipsh K, Sullivan JM, Dietz EO. Health belief assessment regarding screening colonoscopy. Gastroenterol Nurs 2004;27:262-267.

24. Graham ME, Liggons $Y$, Hypolite M. Health beliefs and self breast examination in black women. J Cult Divers 2002;9:49-54.

25. Green PM, Kelly BA. Colorectal cancer knowledge, perceptions, and behaviors in African Americans. Cancer Nurs 27:206-215, 2004; quiz 216-207.
26. James AS, Campbell MK, Hudson MA. Perceived barriers and benefits to colon cancer screening among African Americans in North Carolina: how does perception relate to screening behavior? Cancer Epidemiol Biomarkers Prev 2002;11:529-534.

27. Juniper KC, Oman RF, Hamm RM, Kerby DS. The relationships among constructs in the health belief model and the transtheoretical model among African-American college women for physical activity. Am J Health Promot 2004;18:354-357.

28. Lewis RK, Green BL. Assessing the health attitudes, beliefs, and behaviors of African Americans attending church: a comparison from two communities. J Community Health 2000;25:211-224.

29. Mashegoane S, Moalusi K, Peltzer K, Ngoepe M. The prediction of condom use intention among South African university students. Psychol Rep 2004;95:407-417.

30. McGarvey E, Clavet G, Johnson J, Butler A, et al. Cancer screening practices and attitudes: comparison of low-income women in three ethnic groups. Ethn Health 2003;8:71-82.

31. Norman P, Brain K. An application of an extended health belief model to the prediction of breast self-examination among women with a family history of breast cancer. Br J Health Psychol 2005;10:1-16.

32. Orr D, Langefeld C. Factors associated with condom use by sexually active male adolescents at risk for sexually transmitted disease. Pediatrics 1993;91:873-879.

33. Plowden K, Miller J. Motivators of health seeking behavior in urban African-American men: an exploration of triggers and barriers. J Natl Black Nurses Assoc 2000;11.

34. Plowden KO. Using the health belief model in understanding prostate cancer in African American men. ABNF J 1999;10:4-8.

35. Reese FL, Smith WR. Psychosocial determinants of health care utilization in sickle cell disease patients. Ann Behav Med 1997;19:171-178.

36. Roden J. Validating the revised Health Belief Model for young families: implication for nurses' health promotion practice. Nurs Health Sci 2004;6:247-259.

37. Scollan-Koliopoulos M. Theory-guided intervention for preventing diabetes-related amputations in African Americans. J Vasc Nurs 2004;22:126-133.

38. Sharps PW, El-Mohandes AA, Nabil El-Khorazaty M, Kiely M, et al. Health beliefs and parenting attitudes influence breastfeeding patterns among low-income African-American women. J Perinatol 2003;23:414-419.

39. Steers W, Elliott E, Nemiro J, Ditman D, et al. Health beliefs as predictors of HIV preventive behavior and ethnic differences in prediction. J Soc Psychol 1996;136:99110 .

40. Wiebe JS, Christensen AJ. Health beliefs, personality, and adherence in hemodialysis patients: an interactional perspective. Ann Behav Med 1997;19:30-35.

41. Rowley PT, Loader S, Sutera CJ, Walden M, et al. Prenatal screening for hemoglobinopathies. III. Applicability of the health belief model. Am J Hum Genet 1991;48: 452-459.

42. Barroso J, McMillan S, Casey L, Gibson W, et al. Comparison between AfricanAmerican and white women in their beliefs about breast cancer and their health locus of control. Cancer Nurs 2000;23:268-276.

43. Koontz K, Short AD, Kalinyak K, Noll RB. A randomized, controlled pilot trial of a school intervention for children with sickle cell anemia. J Pediatr Psychol 2004;29: $7-17$.

44. Cummings KM, Jette AM, Rosenstock IM. Construct validation of the health belief model. Health Educ Monogr 1978;6:394-405.

45. Kenen R, Arden-Jones A, Eeles R. We are talking, but are they listening? Communication patterns in families with a history of breast/ovarian cancer (HBOC). Psychooncology 2004;13:335-345.

46. Weil J. Psychosocial Genetic Counseling. New York: Oxford University Press, 2000

47. Goodman MJ, Goodman LE. The overselling of genetic anxiety. Hastings Cent Rep 1982;20-27.

48. Holtzman NA. Promoting safe and effective genetic tests in the United States: work of the task force on genetic testing. Clin Chem 1999;45:732-738.

49. Holtzman NA, Watson MS. Promoting safe and effective genetic testing in the United States. Final report of the Task Force on Genetic Testing. J Child Fam Nurs 1999;2:388-390.

50. Holtzman NMD MPH, Watson MSPD. Final Report of the Task Force on Genetic Testing. In: Neil A, Holtzman MD, Michael S, Watson PD, eds. http://www. genome.gov/10001733. Vol. 2006; 1997.

51. United States Census United States Census Bureau, 2006; available at http://www. census.gov. 